\title{
Repertoire as Motivational Tool for Adult Piano Students
}

\author{
Sviatlana Feshchanka \\ Trinity Laban Conservatoire of Music and Dance, UK
}

\begin{abstract}
In the last decades, adult piano education has become extremely popular. A continuing increase in the numbers of adult piano students' challenges teachers in instrumental studios. As a result, instructors of adult piano students need to be familiar with adult piano methods and concepts to motivate students to succeed. Knowing how students are motivated to learn is crucial for teachers. There are some adults, who become frustrated by the course material, which does not match their level of skills or appropriate grade of learning. Consequently, adult piano students may lose interest in learning and become less motivated. Selecting a piano repertoire that adults find motivating is the key point in the learning process. This article discusses a holistic approach of teaching adults to promote simultaneous learning for better learning outcomes.
\end{abstract}

\section{Introduction}

The main research interest lies in the field of motivational repertoire, including the fundamentals of techniques, sight-reading, ear training, and music theory as the concept of the holistic approach of piano teaching. The current research study includes designing and trialling a tutor book based on the teaching practical experience and data collected from adult piano students. The book consists of technical exercises, etudes, scales and pieces, which provide the foundation for future development of pianist skills. Due to the high interest of adults in learning piano for the last decades, there are more requirements for teachers to meet the criteria of successful learning among adults. Studies of motivation to learn among adults for more than thirty years revealed the essential conditions and placed them in the Motivational Framework for Culturally Responsive Teaching. Motivational conditions such as establishing inclusion, developing a positive attitude, enhancing meaning and competence help accomplish educational equity [1]. Choosing the appropriate repertoire to match the skills of a student is one of the crucial parts in successful learning. Although a number of research have been done towards adult learning, there is a necessity for a 'different approach' for adult methods in comparison with children's curriculum.

\section{Adult Learning and Motivation}

Learning activities of adults in the last decades have gained increased attention from all professional educators to investigate more about musical needs, motivation, and other aspects of music education among lifelong learners. Therefore, music instructors should have more knowledge to make adult learning experience more successful, motivating, and transformational. The main point of teaching adults is the underlying concept of motivation; hence that factor becomes crucial for increasing the level of retention, particularly at the early stage.

Teaching particularly adult students and the nature of the lessons demand an understanding of interactive learning. Music instructors who work with adults should understand that adult student needs more interaction in comparison with children, emotional conversation, and mutual areas of interests, so that enrollment in the program of study will be more pleasurable. Even though some adults recognize the intrinsic value of learning music and find this process already enjoyable, there is still a huge impact from teacher-student emotional relationships on motivation and future growth [2]. The educational research by Meyer and Turner with a main focus on the 're-conceptualizing emotion and motivation' revealed, that 'engaging students in learning requires consistently positive emotional experiences, which forms the foundation for teacherstudent relationships and interactions necessary for motivation to learn' [3]. Wlodkowski supported this idea with one of his guiding principles for enhancing adult motivation, where he stated that 'attention, interest and inspiration are emotional points for learning processes' [4]. At the same time, David Kolb's learning cycle states four stages that help to improve student learning among adults, which are concrete experience, reflective observation, abstract conceptualisation, and active experimentation (see Figure1). Moving forward to active experimentation helps to improve musical capabilities as I have applied this approach into my teaching practice, and it showed several changes among my students. The graphics demonstrate the connection between the four stages of learning: 


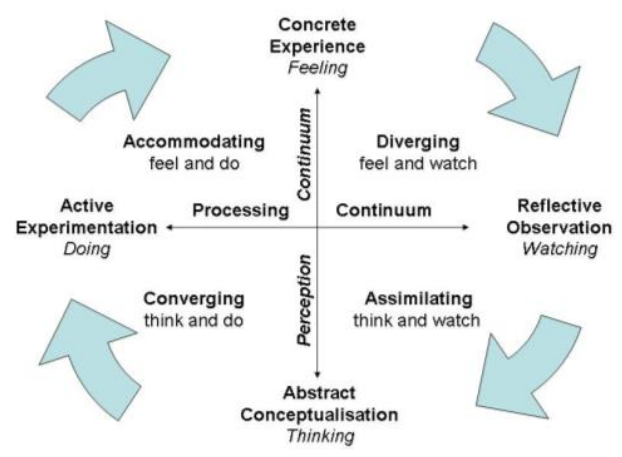

Figure 1. Kolb's Learning Cycle [5]

The most important factor for evaluation of students' progress and learning outcomes rudimentary underlies in the area of motivation. Although some adults could be self-motivated and focused on selfdirected learning, the significant part for the musical development lies on the teachers' responsibility as adults rely on the teacher's guidance to facilitate their musical experiences of achieving goals. At the same time, well-renowned psychologist Carol Dweck explored relationship between people's implicit self-theories and impact on their learning. The two theories by Dweck are known as 'fixed mindset' and 'growth mindset'. According to these theories, adult learning, progression and achievements depends on the type of mindset (see Figure 2).

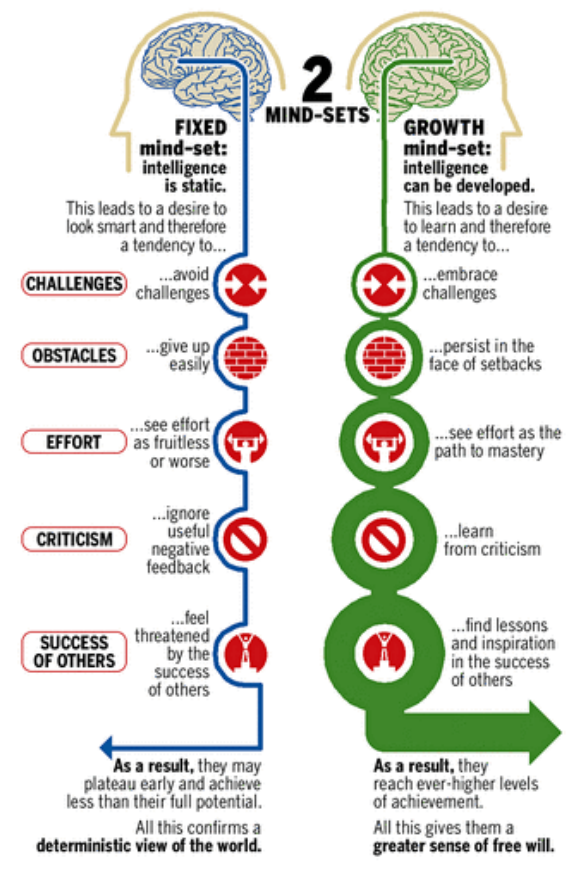

Figure 2. Carol Dweck's mindset theory [6]

The positive characteristics of adults demonstrate that they are analytical, physically coordinated in comparison with young children, and have mature intellects, where 'intellects are often far ahead of their motor capabilities' [7]. From the other side, unrealistic expectations on the abilities and not having enough control of the prerequisite skills needed to reach designed goals with ease, lack of time for practicing or not allowing sufficient time to accomplish desired goals, not knowing how to assess the results of work, and not absorbing teachers' recommendations can bring much more frustration and cause the student to stop classes [8].

Many factors among adults, such as attitude, musical achievement, and coordination, can impact on musical result, self-efficacy and practice in comparison with children [9]. Adult piano beginners have been recognized 'as a central aspect of skill acquisition and individual differences in efficiency of practice' documented in children's beginners' [10]. Moreover, technical abilities of adults differ from children's skills which might bring the most disappointing emotions and failure. Maris reveals two different kinds of learning: cognitive and kinesthetic, where declarative memory (cognitive learning) deals with understanding the concepts and procedural memory (kinesthetic learning) is responsible for muscle control [11].

Adults often become very frustrated as understanding of the music passages (cognitive learning) does not get imbedded into their muscles (kinesthetic learning). Only continuous repetition of certain music patterns can bring learning outcomes and rewards as muscles need to be trained on a daily basis. Unfortunately, not many adults can accept that fact and, more importantly - practice every day; therefore, their technical abilities do not gradually develop as expected and it cause stopping the lessons.

Recently, Wristen's research study stated that the course material brought more frustration than was anticipated at the beginning of the course among her group students [12]. I would like to support this idea with course material as it also brought some frustration in the classroom among my students. As the most motivational tool for starting to play piano, the pieces play a significant role in the progress. Most students want to start piano classes as they would like to play certain pieces, and this becomes the biggest motivational point at the early stage of learning. Conclusion of the research on motivation for adult piano learners provides insight into the significant role that technical improvement, selfgrowth, setting high performance goals, and variety of adult repertoire play for bringing musical achievement, self-confidence, and effectiveness of learning. As a result of this research study, I created an Adult Piano Method for beginners with a main focus on technique, an adult piano repertoire with broad range of musical styles and genres, ear training and music appreciation. Adults particularly enjoy 
listening to the teacher's playing, so several suggestions on inclusion of appreciative music pieces are added in the lessons of the book. My research study proved that listening to the teacher's performance becomes very motivational for the students, so inclusion of that activity in the lesson was very rewarding. Several pieces included in my piano method were also tested on my students and have shown the gradual technical progress and enjoyment from the process of learning. Consistent practice of warm-ups, technical exercises and etudes improve development of motor-cognition skills and, as a result, promote self-confidence, self-esteem, and satisfaction from the progress. In a short summary, the issues of adult piano learning reveal the link between motivation, motor-cognition skills, selfconfidence, and self-esteem. More widely, pedagogical literature that addresses the problems of adult learning points out mindset factors and theories, psychological struggles and selfimprovement, social and emotional contexts.

\section{Presentation of my Adult Piano Method}

The aim of creating the adult piano curriculum was caused by the necessity of applying relevant methods of teaching for adult piano beginners. Limited research in this area has been published. Regrettably, there is no evidence of existing methods for teaching adult piano beginners with inclusion of contemporary, modern pieces and current compositions. Exploration of the publishing market and analysis of presented adult piano methods on the shelves of music shops have shown that there are many old syllabuses with the content of learning as the same as many decades ago or newly published adult piano methods with old pop tunes, children's songs and nursery rhymes. Based on my research study, adults share their thoughts on repertoire and pieces, which would make them more satisfied, motivated, and fulfilled with accomplishing their goals and dreams. Most of my interviewed students replied that the most motivational tool for them is playing piano pieces of their choice - mostly contemporary or famous classics - and not to be stacked with children's songs or old pop tunes. Music theory combined with basic note reading, defining intervallic and key relationships, analysis of basic tertian and chord harmony are recognized by students as the most acceptable concept for developing music literacy [13]. Initial technical exercises connected with chord progression and rhythmical patterns of the pieces helped to familiarize basic concepts of music theory and integrate this knowledge into practice. As a result, it promotes technical abilities and develops metacognition. Also, one of my students commented that music theory as a separate book becomes 'boring', but a combination of some music theory with pieces and technical exercises is the right thing. The technical aspects of learning and technical progression are the main accents during the study. The great piano teacher Leschetizky made a huge impact on process of developing technical skills, which influenced the creation of The Groundwork of the Leschetizky Method with nearly one hundred pages and twenty-eight sections, containing verbal text, technical exercises, and excerpts from pieces [14]. This idea of matching the technical exercises and pieces in relation of harmonic chords was my inspiration from the Leschetizky Method to create a holistic approach.

Leschetizky's concept on developing following technical elements led to the inclusion of such technical exercises as:

- Touches (non-legato, legato, staccato)

- Scales

- Arpeggios

- Broken chords

- Ornaments

- Double thirds and double notes

- Repeated notes

- Chords

- Leaps

The concept of technical development with those technical elements was embedded in the author's designed method book as one of the parts of a holistic approach. In addition of technical foundation, I included triplets, different rhythmical patterns containing syncopation and jazz articulation. Therefore, the creation the curriculum for adults based on the concept of a holistic approach became a necessity. No doubt, many adults might have a different opinion on the repertoire and styles preferences, but the common ground for all of them is combination of theory, technical exercises, and practice. This curriculum will integrate the most effective and appropriate learning and teaching strategies that will suit adult piano students. The fundamental of this adult piano method is a holistic approach of teaching, which combines such learning activities as playing warm-ups, technical exercises, pieces, piano duets, music theory, improvisation, and ear-training all in one lesson. Some activities might be given as self-practice for homework. Therefore, the piano curriculum for adults integrates the following concepts of music learning:

- Development of technique from the early stage of learning (technical exercises, warm-ups, scales, small etudes).

- Contemporary pieces and folk/national songs (British, Spanish, Italian, French tunes as 
presentation of the culture of different countries of the EU).

- Piano duets (development of ensemble skills).

- Improvisation based on learning current pieces.

- Ear-training (might include either listening to teacher performance of desired songs and music appreciation activity as adults find it a very motivating strategy or aural skills development, based on the current lessons' learning program).

- Music theory (fundamentals, based on the current lessons' program).

The piano book consists of twelve lessons, which includes structured studies for every lesson for beginners. The choice of twelve lessons for beginners is based on the term time to achieve the best results.

\section{Data Collection}

Based on reflexive cycles of action research, which include such stages as planning a change, observing that change, reflecting on it, planning and observing again, I made two iterative cycles, which helped to gather data for my research [15]. All data were collected between the end of April and the end of September. The participants of my research were adult piano learners of beginner and intermediate levels. Some of them were complete beginners and some had previous piano experience with other teachers in different countries. For that reason, I have chosen to include four adult students in this research study to complete representation from different learning backgrounds. The participants were as follows:

A: Female, learner for 9 months, pupil for 9 months. B: Female, learner for 7 years, pupil for 7 months.

C: Female, learner for 5 years, pupil for 5 months.

D: Female, learner for 7 months, pupil for 7 months.

Many of my adult students struggle to have regular lessons, especially during summertime. All my adult students have a good communication level and followed up with the homework given. Many of my students practice on a regular basis and showed good progress results. Even though, sometimes they did not have a chance to practice at home, they have been focused on the lessons and were attentive to details. As a teacher, I was happy that all of them agreed to participate in this research study and some of them really showed great interest and asked about my study and how it had been progressing. Due to lack of regular lessons for some of my students, I investigated what is the most motivational tool for their learning, so they would continue to come for the lessons. Even though the grade levels for all students are different, most importantly motivation is the unifying factor for judging all of them. Keeping in mind teaching strategies with impact on intrinsic motivation, also known as 'self-concept, self-esteem, self-satisfaction, personal values, and personal / emotional needs', my pedagogical principles are based on transformative pedagogy, musical collaboration in every aspect of students' learning, encouragement, promoting self-motivation among them and maximum involvement in repertoire selection to achieve great results [16]. During my first iterative cycle of action research, I tried to investigate more about my students' motivation and self-motivation, personal values, and their selfsatisfaction, finally, what brings more joy and selfefficacy from their learning process.

\subsection{First Round}

In the first-round task, the students were informed about the upcoming research study as an introduction. After introduction to action research and its aims, I asked if they would like to participate in this study, which would include interviews and video recordings. Luckily, all my adult students agreed to become the participants of this research. Therefore, they were given a consent form to sign as an agreement for recordings and using their data. After that, we agreed on making the interview at a suggested time right after the lesson and which lasted for approximately 7-10 minutes.

4.1.1. The Reflection. Upon completion of all interviews, there were some positive and negative comments, suggestions, and recommendations. Some positive comments included the interest in a holistic approach of teaching, which helps students to understand the concepts of music more deeply. Negative comments were about children's songs in the syllabus, lack of time to practice and boredom from learning music theory.

For example, participant $\mathrm{C}$ suggested including theory with practical material as it connected to pieces, rather than keeping a music theory book as a separate toolkit. Participant D prefers to play pieces not only from Alfred's Piano Course, as it has a lot of material for children, but also some folk and national tunes from her homeland. Due to the first question in our interviews being about motivation, many participants replied that pieces are the most motivational tool for learning piano, and also the fact, that the teacher knows how to teach certain pieces to play. As a fact, participant B used to play a maximum 2-3 pieces for a whole year when she was a child. Now her progress has been raised and we learned three etudes on the development of different techniques, two pieces, Beethoven's Sonata and Tango in D by Albeniz - for seven months. Her reflections on it were that the holistic approach, 
dedicated practice and chosen pieces led her to improve her skills overall.

\subsection{Second Round}

In the second-round task, students were given approximately 3-4 months between the first and second round to provide feedback upon completion of the tasks. Intentionally, I gave a period of time to adapt the first interviews to the requirements of participants. I changed the lesson plans with inclusion of the necessary musical aspects for the growth of my students. I provided the instruction built on the feedback from the first round. The students were informed about the second interview in advance - one week ahead of the lesson. They were asked about the motivation, the learned pieces with the new holistic approach, progress and how these factors impacted on their musical development. Also, videotaping of the lessons helped to gather more evidence for data and to provide analytical overviews of the progress.

4.2.1. The Reflection. Three of my students have shown a positive impact of the holistic approach on their technical development and learning outcomes. As a creator I am happy to see the technical progress of my three students due to a main focus on technical exercises, warm-ups, and etudes as the main fundamentals for building-up of the technical foundation of a pianist. The fourth student did not show much progress due to absence of a piano, constant practice, and high-performance goals, which proved the correlation between ambitions, progress and practice. However, from a teacher's perspective, there is still a tendency for a self-criticism to improve the holistic approach with more different kinds of exercises to satisfy all aspects of a pianist's progress. At the same time, this approach was created as the main focus to improve my students' musical skills and meet individual musical expectations. The concept of motivation refers to the repertoire, motor-cognitive skills, self-confidence, and emotional teacher-student relationships. The holistic approach referred to pedagogical strategies and methods of teaching, combination of subjects such as music theory, technical exercises, etudes, ear, training, improvisation, composition.

\section{Data Analysis}

To maximize the reflections of students for the widest ranged data, I chose four students with different backgrounds of learning pace and levels of musicianship. Also, two of them used to play in childhood. So, I considered it as potential to gather a broader range of motivational tools, keeping in mind the question: "What made you motivated to start piano lessons again?" The group comprised four females, age ranged from mid-twenties to midthirties and all different nationalities.

The whole purpose of interview was to make an analysis of my teaching practice and gain insight into my concepts of pedagogy, gaining feedback from students on my holistic approach and gathering more data about the motivation of adults. Semi-structured interviews were conducted throughout the research study process, which allowed having a more individualized approach to each student, based on their level and progress. Interview questions were categorized in five main types:

- Motivation to start and continue piano lessons.

- Best learning material (video lesson, book, online, any other technology).

- The most preferred musical styles to learn and to see in adult piano books.

- Suggestions on adult piano books.

- Combination of musical aspects in one book and feedback on presentation of my holistic approach

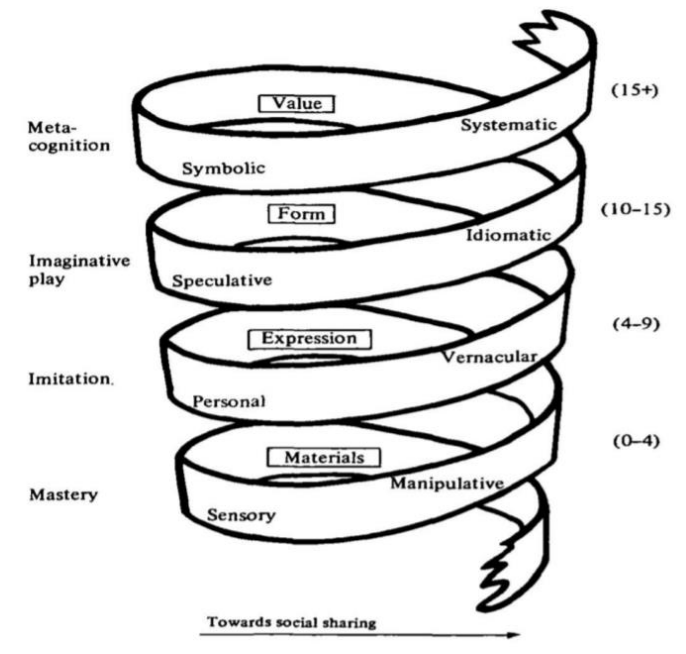

Figure 3. Swanwick's developmental model [17].

I tried to maintain a conversational manner of taking interviews as much as possible and putting more words into questions so that students felt more relaxed and more open to the length of interviews. The interview data were coded under three concepts:

- Motivation (what motivates adult piano students).

- Holistic approach (students' feedback on my approach).

- Concept of progress.

The four levels of musical criticism, such as materials, expression, form, and value, were concerned as control of sound, perception of expressive character of music, and mastery of artistry. The spiral developmental model and musical criticism with four dimensions of music were 
considered as the main theoretical framework and view of musical progress (see Figure 3).

\section{Methodology}

Action research perfectly matches educational context as it enquires into the teaching practice. Ortrun Zuber-Skerritt influenced the definition of action research as an appropriate research paradigm for educational, professional and organizational development [18]. Therefore, the strength of current action research is changing the individuals, educational system, and teaching methods through the planning, acting, observation and reflection. The plan of the current action research consists of the four following steps (see Figure 4).

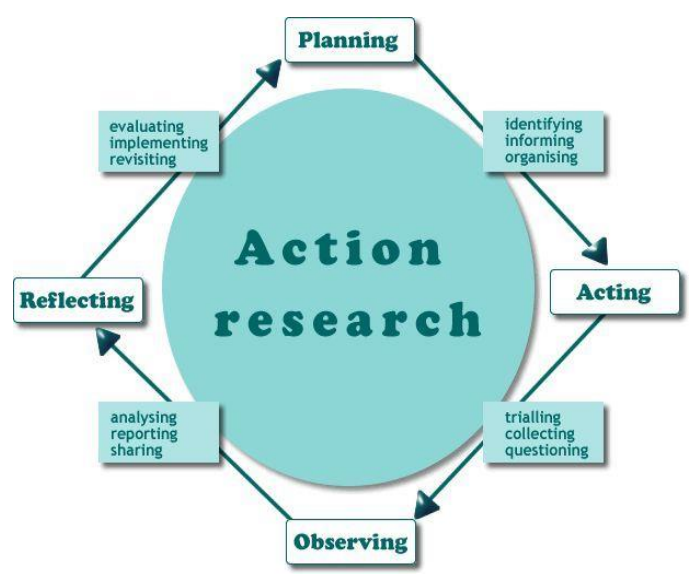

Figure 4. Action research cycle [19]

Current research combines critically reflective theory and practice with a focus on critical action research. Ortrun Zuber-Skerritt impacted on an appropriate action research as it sharpens critical and self-critical inquiry by practitioners as main issues in teaching practice, which are definitive features of critical action research.

\section{Research Findings}

The key findings of the research study show the strong correlation between motivation, choice of repertoire, holistic approach of teaching and technical progress. The interviews analysis revealed that adults prefer the classically trained approach of teaching piano with elements of contemporary music and variety of genres and styles included in the syllabus. There is also a tendency to a printed version of a piano book in comparison with online courses or video lessons which proves possession of traditional ways of learning rather than any other digital learning alternatives. Moreover, a holistic approach of learning piano with individual access to abilities of each student has shown positive impact on the technical progress and meta-cognition.

\section{Conclusion}

Exploration of pedagogical literature provides insight into the important role that mindsets, social context, setting of performance goals, deliberate practice play in the progress and learning outcomes. It is a positive stimulus that growth mindset correlates with progress, motivation and encouragement; therefore. Piano teachers can apply these elements into teaching practice and strategy for better results of students. At the same time, research study has shown that enjoyment, self-confidence, satisfaction from progress, repertoire and choice of pieces have a significant impact on motivation of adults. A holistic approach of teaching, which was applied into my teaching practice, demonstrated a technical progress and motor cognition skills, and emphasised students' personal and musical development. The inclusion of technical fundamentals into my comprehensive approach and creation of adult piano method in regard of individual characteristics and abilities of adults contributed to better learning outcomes. Examination of common problems of excessive muscular tension, inefficient coordination and systematic practice among some adult beginners, which inhibit students' musical development, influenced on inclusion of exercises during the lessons and inside of the book. The created adult piano method establishes the concept of a holistic approach and intends to improve artistic abilities, technical development and interpretation among adult piano beginners for fulfilment of musical potential.

\section{References}

[1] Wlodkowski, R.J., and Ginsberg, M.B., (2017). Enhancing adult motivation to learn: A comprehensive guide for teaching all adults. John Wiley and Sons.

[2] Wristen, B., (2006). "Demographics and motivation of adult group piano students." Music Education Research 8, no. $3: 387-406$.

[3] Meyer, D.K., and Turner, J.C., (2006). "Reconceptualizing emotion and motivation to learn in classroom contexts. "Educational Psychology Review 18, no. $4: 377-390$.

[4] Wlodkowski, R.J., and Ginsberg, M.B., (2017). Enhancing adult motivation to learn: A comprehensive guide for teaching all adults. John Wiley and Sons.

[5] Stice, J.E., (1987). "Using Kolb's Learning Cycle to Improve Student Learning." Engineering Education, 77, no. 5 : 291-96.

[6] Dweck, C.S., (2006). Mindset: the new psychology of success. New York: Random House.

[7] Orlofsky, D. D., and Smith, R., (1997). "Strategies for 
Adult Keyboard Learners: Adult students have distinctive learning characteristics and need special pedagogical strategies to increase their enjoyment and success at the keyboard." Music Educators Journal 83, no. 4 : 22-26.

[8] Maris, B.E., (2000). Making music at the piano: Learning strategies for adult students. Oxford University Press on Demand.

[9] Burgos, J.A., and High, L., (2009). "Perceived versus actual practice strategy usage by older adult novice piano students. "Visions of research in Music Education 13, no. 1: $1-26$.

[10] Lehmann, A.C., and Papousek, S., (2003). "Selfreported performance goals predict actual practice behaviour among adult piano beginners." In Proceedings of the 5th Triennial Conference of the European Society for Cognitive Sciences of Music, pp. 389-392.

[11] Maris, B.E., (2000). Making music at the piano: Learning strategies for adult students. Oxford University Press on Demand.

[12] Wristen, B., (2006). "Demographics and motivation of adult group piano students." Music Education Research 8, no. $3: 387-406$.

[13] Bugos, J.A., and High, L., (2009). "Perceived versus actual practice strategy usage by older adult novice piano students. "Visions of research in Music Education 13, no. 1 : $1-26$.

[14] Gerig, R.R., (1975). Famous pianists and their technique. RB Luce.

[15] Kemmis, S., (2008). "Critical theory and participatory action research." The SAGE handbook of action research: Participative inquiry and practice $2: 121-138$.

[16] Bomia, L., Beluzo, L., Demeester, D., Elander, K., Johnson, M., and Sheldon, B., (1997). "The Impact of Teaching Strategies on Intrinsic Motivation".

[17] Swanwick, K., (2003). Music, Mind and Education. Routledge.

[18] Zuber-Skerritt, O., ed. New directions in action research. Routledge, 2003.

[19] Saad, R., Mohd Saifudin, A., and Yaacob, A., (2015). Computer Competency Will Enhance Statistical Literacy. GSM e-Journal of Education. 3: 23-33. (17 June 2021).

[20] Dweck, C. S., (2007). "Self-theories: The mindset of a champion." Sport and exercise psychology: International perspectives : $15-23$.

[21] Dweck, C., (2012). Mindset: Changing the way you think to fulfil your potential. Hachette UK. 